ББК $65.305 .143 .2-21$

И. С. Кородюк

Байкальский государственный университет, г. Иркутск, Российская Федераиия

С. Е. Трофимов

Байкальский государственный университет, 2. Иркутск, Российская Федерация

\title{
НЕФТЕГАЗОВЫЙ КОМПЛЕКС РОССИИ КАК ОБЪЕКТ ГОСУДАРСТВЕННОГО РЕГУЛИРОВАНИЯ
}

\begin{abstract}
АНнотАЦИЯ. В статье рассмотрена рыночная эволюция механизма государственного регулирования отечественного нефтегазового комплекса. Показан двойственный характер современного процесса регулирования энергетического сектора страны, который осуществляется, как за счет прямого централизованного воздействия на хозяйствующих субъектов, так и за счет внутренних возможностей рыночного механизма использовать собственные инструменты для решения поставленных задач. Проанализированы отдельные аспекты специфики государственного регулирования национального нефтегазового комплекса. Сделан вывод о повышении роли государственного регулирования энергетического сектора России в условиях экономического кризиса и западной санкционной политики.

кЛючЕВЫЕ словА. Нефтегазовый комплекс; плановая экономика; рыночная экономика; механизм государственного регулирования нефтегазового комплекса; лицензирование; система налогообложения; инвестиционная политика; внешнеполитические вызовы.

ИНФОРМАЦИЯ О СТАТЬЕ. Дата поступления 10 апреля 2017 г.; дата принятия к печати 18 мая 2017 г.; дата онлайн-размещения 19 июня 2017 г.
\end{abstract}

I. S. Korodyuk Baikal State University, Irkutsk, Russian Federation

S. E. Trofimov

Baikal State University, Irkutsk, Russian Federation

\section{RUSSIAN OIL AND GAS COMPLEX AS AN OBJECT OF GOVERNMENTAL REGULATION}

ABSTRACT. The article examines market evolution of governmental regulation of the national oil and gas complex. It shows the dual nature of modern process of regulating the country's energy sector which is performed both at the expense of the direct centralized impact on economic entities and at the expense of internal possibilities of the market mechanism to use their own instruments for completing the tasks set. It analyses separate specific aspects of governmental regulation of the national oil and gas complex. A conclusion is drawn about increasing the role of governmental regulation of Russia's energetic sector in terms of the economic crisis and western sanctional policy. KEYWORDS. Oil and gas complex; planned economy; market economy; mechanism of governmental regulation of oil and gas complex; licensing; taxation system; investment policy; foreign policy challenges.

ARTICLE INFO. Received April 10, 2017; accepted May 18, 2017; available online June 19, 2017.

В конце XX - начале XXI в. механизм государственного регулирования отечественного нефтегазового комплекса (НГК) претерпел кардинальные изменения. Так, в советский период планирование в СССР носило исключительно директив-

(C) И. С. Кородюк, С. Е. Трофимов, 2017

\section{Baikal Research Journal}


ный характер, экономика страны и ее отдельные отрасли развивались как единый народнохозяйственный комплекс, в основе которого лежала марксистская модель развития. Предприятия нефтегазовой промышленности, как и другие структурные звенья экономики, в централизованном порядке получали плановые показатели, обязательные для выполнения [1].

Переход в начале 90-х гг. ХХ в. к рынку сопровождался различными подходами государственного регулирования двух составляющих НГК: нефтяной и газовой промышленности. В наибольшей степени процесс разгосударствления и приватизации затронул нефтяной сектор экономики, когда на основе Министерства нефтяной промышленности СССР возникли десятки независимых компаний, в том числе региональные монополисты (ОАО «Татнефть», OAO «Башнефть»), государственное регулирование которых осуществлялось на основе монетарной модели. Большинство из этих компаний были с экономической точки зрения слабы и имели низкий уровень капитализации. Высокие налоговые ставки, отсутствие централизованного финансирования, крайняя степень изношенности основных фондов, кризис неплатежеспособности в условиях углубляющегося экономического кризиса привели к тому, что многие из них заявили о своей несостоятельности и банкротстве [2]. Поэтому Постановлением Правительства РФ № 971 от 29 сентября 1995 г. было создано ОАО «Нефтяная компания «Роснефть», контрольный пакет акций которой принадлежал государству, а в 1998 г. в собственность государства перешли пакеты акций еще шести нефтяных компаний. Кроме того, в это же время было создано 15 вертикально интегрированных нефтегазовых компаний с высокой степенью участия федерального центра.

Рыночная реформа государственного регулирования газового сектора экономики носила более взвешенный характер. В 1989 г. на базе Министерства газовой промышленности СССР был создан Государственный газовый концерн «Газпром» . В дальнейшем он стал своеобразной платформой для акционирования предприятия (РАО «Газпром», 1993 г.), а в 1998 г. был переименован в ОАО «Газпром», контрольный пакет акций которого также принадлежит государству. Это позволило сохранить газовую отрасль в качестве относительно целостной самостоятельной системы, что способствовало выполнению международных контрактов и обеспечению надежного газоснабжения населения страны по низким внутренним ценам.

В газовом секторе по сравнению с другими отраслями экономики значительно шире используются прямые методы государственного регулирования: установление плановых показателей добычи газа, контроль над ценами на углеводородное сырье и др. Повышению эффективности государственного регулирования способствовала также контролируемая из Центра газотранспортная инфраструктура. Не случайно в начале 1990-х гг. газ стал занимать лидирующие позиции во внешнеторговом балансе России.

После дефолта 1998 г. Правительство РФ стало широко использовать не только синтез кейнсианского и неоклассических направлений, но и новые институциональные подходы, применяемые к конкретным условиям, что в определенной степени позволило говорить о размытии границ между моделями государственного регулирования экономики. На современном этапе механизм государственного регулирования НГК Российской Федерации, являясь в соответствии с системно-функциональным подходом составной частью механизма государственного регулирования экономики, в своей основе подразумевает прагматизм при добыче, распределении и использовании углеводородных ресурсов. Опыт 1990-х гг. наглядно показал, что нет необходимости досконально следовать предложениям и рекомендациям по развитию экономики, поступающим от зарубежных политиков, международных экспертов и финансовых организаций, зачастую преследующих

\section{Baikal Research Journal}

электронный научный журнал Байкальского государственного университета 
свои собственные интересы [3]. Гораздо продуктивнее, опираясь на национальные интересы и с учетом передового зарубежного опыта, выстроить собственную систему эффективного регулирования НГК.

Процесс регулирования НГК осуществляется, с одной стороны, за счет прямого воздействия правительственных органов на нефтедобывающие компании, с другой - за счет внутренних возможностей рыночного механизма использовать собственные рычаги для реализации поставленных конкретных целей или задач. Например, лицензирование нефтегазовой деятельности в РФ носит исключительно административный характер со стороны Министерства природных ресурсов РФ и предполагает установление сроков действия лицензии, указание сведений о разрабатываемом участке недр и другие показатели. Государство контролирует экономический рост в НГК, деятельность крупнейших отраслевых фирм в рамках антимонопольной, таможенно-тарифной и трудовой политики.

Важную регулирующую роль в развитии отечественного НГК играет система налогообложения. Она должна способствовать решению двух основных задач: стимулирование производства в энергетическом секторе, а также увеличение нефтегазовых доходов федерального бюджета [4]. В России налогообложение НГК претерпело кардинальные изменения после проведения налоговой реформы, в результате которой система изъятия ресурсных доходов посредством введения налога на добычу полезных ископаемых (НДПИ) и экспортных пошлин стала более гибкой. Она была введена с 2002 г. и позволила решить проблему трансфертного ценообразования, а также повысить налоговые поступления. В предложенной системе налогообложения предприятий НГК удельный вес нефтегазовой ренты, поступающей в бюджет, прямо пропорционален сложившемуся уровню мировых цен на нефть.

В результате реформы налоговые ставки НДПИ по нефти изменялись следующим образом: $2002-2003$ гг. - 340 р./т, 2004 г. - 347 р./т, 2005-2011 гг. 419 р./т, 2012 г. - 446 р./т, 2013 г. - 470 р./т, 2014 г. - 493 р./т. В 2014 г. налоговая нагрузка на предприятия НГК была перераспределена: НДПИ был увеличен, в то время как экспортные пошлины снизились. Это продиктовано тем, что налоговая нагрузка на внутреннем рынке была ниже, чем при экспортных поставках. В 2015 г. налоговая ставка составила 766 р./т, на 2016 и 2017 гг. установлена в размере 857 р./т и 919 р./т соответственно. С 1 января 2009 г. НДПИ на нефть рассчитывается Правительством РФ, исходя из цены отсечения в 15 дол./баррель. В 2005-2008 гг. цена отсечения НДПИ составляла 9 дол./баррель, в 2002-2005 гг. - 8 дол./баррель ${ }^{1}$.

С 2002 г. установленная ставка корректируется на определенные коэффициенты. В 2002-2006 гг. НДПИ на нефть рассчитывался по следующей формуле:

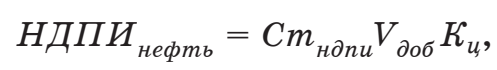

где $C m_{\text {ндпи }}$ - налоговая ставка по НДПИ; $V_{\text {доб }}$ - объем добытого сырья на месторождении; $K_{u}-$ коэффициент, показывающий изменение цен на нефть в мире, публикуется ежемесячно в «Российской газете».

В 2007-2011 гг. расчет НДПИ по нефти происходил по формуле:

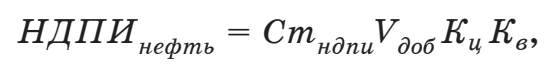

где $K_{6}-$ коэффициент, показывающий степень выработки месторождения; определяется по данным государственного баланса на 1 января 2006 г. Принимает понижающее значение при выработке месторождения свыше 80 \% .

\footnotetext{
1 Данные, применяемые для расчета налога на добычу полезных ископаемых в отношении нефти (в целях применения главы 26 Налогового кодекса РФ) [Электронный ресурс] // СПС «КонсультантПлюс».
}

\section{Baikal Research Journal}


В период с 1 января 2012 г. по 31 августа 2013 г. ставка НДПИ корректировалась также на $K_{3}$ - коэффициент, характеризующий величину запасов конкретного участка недр, а с 1 сентября 2013 г. по 31 декабря 2014 г. - на $K_{\partial}$ и $K_{\partial \varepsilon}$. Данные коэффициенты характеризуют степень сложности добычи нефти и степень выработанности конкретной залежи углеводородного сырья соответственно. Коэффициент $K_{\partial \varepsilon}$ определяется по данным государственного баланса на 1 января года, предшествующего налоговому периоду, и принимает понижающее значение при выработке месторождения свыше $80 \%$.

С 2015 г. расчет НДПИ на нефть происходит по следующей формуле:

$$
\text { НДП }{ }_{\text {нефть }}=C m_{\text {ндии }} V_{\text {доб }} K_{u}\left(1-K_{в} K_{3} K_{\partial} K_{\partial в} K_{\text {кан }}\right) \text {, }
$$

где $K_{\text {кан }}$ - коэффициент, характеризующий регион добычи и свойства нефти.

Льготой при расчете НДПИ является снижение объема выработки на месторождении на величину нормативных потерь и добычи попутного нефтяного газа.

Стоит отметить, что в связи с падением мировых цен на углеводородное сырье в 2014-2016 гг. на правительственном уровне обсуждался вопрос сокращения налоговой нагрузки для добывающих компаний. Например, предлагалось осуществить налоговый маневр, при котором базовая ставка по НДПИ увеличивалась бы с 766 до 795 р./т, однако при этом повышалась цена отсечения с 15 до 18 дол./баррель. Ранее высказывались предложения по ее увеличению до 25 дол./баррель [5] При этом коэффициент изменения цен в 2015 г. рассчитывался как:

$$
\kappa_{u}=(Ц-15) P / 261,
$$

где $Ц$ - среднемесячная цена нефти Urals в портах Роттердама и Средиземного моря; $P$ - среднемесячный курс рубля к доллару США.

Понижающие коэффициенты к ставке НДПИ $K_{\varepsilon}$ и $K_{\partial в}$ рассчитываются по формуле:

$$
\kappa_{B}=3,8-3,5(N / V),
$$

где $N$ - накопленный объем добычи нефти на месторождении; $V$ - объем запасов $A+B+C_{1}+C_{2}$ месторождения в соответствии с российской системой классификации. Отличие двух коэффициентов состоит в том, что используются различные даты государственного баланса.

Таким образом, каждый процент выработанности месторождения сверх 80 \% дает $3,5 \%$ экономии на НДПИ на нефть. К крупнейшим выработанным более чем на $80 \%$ нефтяным месторождениям на сегодняшний день относятся Мамонтовское («Роснефть») и Ромашкинское («Татнефть»), где этот показатель составил 85 \% .

Коэффициент величины запасов нефтяных месторождений $K_{3}$ в соответствии с Налоговым кодексом РФ рассчитывается как:

$$
K_{3}=0,125 V_{3}+0,375,
$$

где $V_{3}$ - начальные извлекаемые запасы $A+B+C_{1}+C_{2}$ в млн т на 1 января года, предшествующего году налогового периода, и накопленной добычи нефти с начала разработки конкретного участка недр в соответствии с данными государственного баланса запаса полезных ископаемых, утверж-денного в году, предшествующем году налогового периода ${ }^{2}$.

С 1 июля 2014 г. была изменена методика исчисления НДПИ на природный газ. Ранее данный налог рассчитывался как произведение ставки налога на объем добытого природного газа в тыс. $\mathrm{M}^{3}$ :

${ }^{2}$ Налоговый кодекс Российской Федерации. Часть вторая : федер. закон от 5 авг. 2000 г. № 117-ФЗ (в ред. от 3 апр. 2017 г.). Ст. 342, 342.2, 342.5 // СПС «КонсультантПлюс».

\section{Baikal Research Journal}




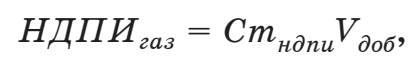

где $C m_{\text {нди }}-$ ставка НДПИ на природный газ; $V_{\text {доб }}$ - объем добытого природного газа, тыс. $\mathbf{m}^{3}$.

В 2006-2010 гг. ставка НДПИ составляла 147 р./тыс. м ${ }^{3}$, в 2011 г. - 237 р./ тыс. $\mathrm{m}^{3}$ (в соответствии с темпами инфляции - $61 \%$ за неиндексируемые годы), в 2012 г. - 251 р./тыс. м ${ }^{3}$, в 2013 г. - 265 р./тыс. м ${ }^{3}$. В 2014 г. ставка налога установлена в размере $35 \mathrm{p}$./тыс. $\mathrm{m}^{3}$, а его исчисление производится по формуле:

$$
\text { НДП } \text { газ }=V_{\text {доб }}\left(35 E_{y m} \kappa_{c}+T_{2}\right),
$$

где $E_{y m}-$ базовое значение единицы условного топлива; $K_{c}-$ коэффициент, характеризующий степень сложности добычи газа; $T_{2}-$ показатель, характеризующий расходы на транспортировку газа.

Все показатели рассчитываются в соответствии с Налоговым кодексом РФ и учитывают множество факторов, включая цену природного газа, объем его добычи, степень выработанности запасов конкретного участка недр, его географическое расположение и принадлежность к региональной системе газоснабжения, экспортную доходность единицы условного топлива, глубину залегания углеводородных запасов, особенности их разработки и др. ${ }^{3}$

В силу относительно высокого налогообложения нефтегазовой отрасли стимулирование ее развития осуществляется за счет определенных мер государственной поддержки. К основным из них относятся:

- пониженные ставки вывозной таможенной пошлины на нефть и предоставление налоговых каникул по НДПИ для месторождений Восточной Сибири, выработанных менее чем на $5 \%$;

- налоговые каникулы по НДПИ для новых месторождений полуострова Ямал, ряда месторождений континентального шельфа России, в частности Черного и Охотского морей;

- применение понижающего коэффициента к ставке НДПИ для малых и истощенных месторождений;

- субсидирование геолого-разведочных работ;

- применение механизмов ускоренной амортизации;

- различные налоговые льготы при исчислении налога на прибыль, транспортировке углеводородов и др. ${ }^{4}[6-8]$.

Нефтегазовый сектор по праву считается одной из самых капиталоемких отраслей, использующих наиболее дорогостоящее оборудование, технологии, квалифицированную рабочую силу. Развитие НГК сопровождается появлением новых рабочих мест, стимулирует производство в смежных отраслях, которые создают мультипликативный эффект для ведения предпринимательской деятельности, что, в свою очередь, открывает новые инвестиционные возможности. Поэтому для ресурсодобывающих компаний огромное значение имеет вопрос приобретения долгосрочного дешевого заемного капитала и привлечения кредитных ресурсов, в том числе, когда это возможно, на более дешевых зарубежных финансовых рынках.

Практически все нефтегазовые компании финансируют часть текущей деятельности за счет заемных средств. В частности, в начале 2015 г. Иркутская нефтяная компания получила транш на развитие в размере 150 млн дол. от Европейского банка реконструкции и развития, что с позиции санкционной политики

\footnotetext{
${ }^{3}$ Налоговый кодекс Российской Федерации. Часть вторая. Ст. 342, 342.4.

4 Налоговый кодекс Российской Федерации. Часть вторая ; Энергетическая стратегия России на период до 2030 г. : распоряжение Правительства РФ от 13 нояб. 2009 г. № 1715-р // СПС «КонсультантПлюс» ; Энергетическая стратегия России на период до 2035 г. : проект (в ред. от 21 сент. 2016 г.) // Министерство энергетики РФ. URL: http://minenergo.gov.ru/node/1920.
}

\section{Baikal Research Journal}


в отношении России можно рассматривать, скорее, как исключение. Примером международного кредитования российского нефтегазового сектора вполне могло стать предоставление долгосрочных финансовых ресурсов Правительством КНР на строительство газопровода «Сила Сибири». Однако Правительство РФ и руководство ПАО «Газпром» решили обойтись собственными средствами в связи с не совсем приемлемыми условиями предоставления кредита международными партнерами и возможными экономическими рисками.

Привлечение кредитных ресурсов служит весомым фактором наращивания объемов производства и повышения капитализации предприятий, обладающих высоким кредитным рейтингом. Льготные кредиты из Фонда развития промышленности по ставке 5-6\% могут получать с 2014 г. производители, ориентированные на модернизацию, организацию новых производств и импортозамещение нефтегазового оборудования ${ }^{5}$. Кроме того, постановлением Правительства РФ от 11 октября 2014 г. № 1044 утверждена и успешно функционирует государственная Программа поддержки инвестиционных проектов, реализуемых на основе проектного финансирования.

На современном этапе НГК представляет собой главное структурное звено отечественной экономики, осуществляющее свою деятельность в условиях западной санкционной политики, когда относительно более дешевые кредитные ресурсы и передовые зарубежные технологии становятся в ряде случаев недоступными для российских компаний, занимающихся освоением нефтегазовых запасов. Внешнеполитические вызовы повышают роль и значение государственного регулирования НГК РФ, которое позволяет эффективнее использовать отечественные углеводородные месторождения, являющиеся одним из важнейших конкурентных преимуществ национальной экономики.

\section{Список использованной литературы}

1. Интенсификация и эффективность социалистического производства / А. Г. Аганбегян [и др.]. - М. : Наука, 1988. - 407 с.

2. Шмелев Н. П. В поисках здравого смысла. Двадцать лет российских экономических реформ / Н. П. Шмелев. - М. : Весь мир, 2009. - 514 с.

3. Гайдар Е. Т. Гибель империи. Уроки для современной России / Е. Т. Гайдар. 2-е изд., испр. и доп. - М. : РОССПЭН, 2006. - 448 с.

4. Гурвич Е. Т. Нефтегазовая рента в российской экономике / Е. Т. Гурвич // Вопросы экономики. -2010 . - № 11. - С. 4-24.

5. Папченкова М. Нефтяники рассчитывают добиться снижения налоговой нагрузки из-за падения цены на нефть [Электронный ресурс] / М. Папченкова. - Режим доступа: http://www.vedomosti.ru/business/articles/2015/02/02/ novaya-cena-manevra.

6. Бобылев Ю. Н. Мировой опыт налогообложения добывающей промышленности / Ю. Н. Бобылев. - М. : Рос. акад. нар. хоз-ва и гос. службы при Президенте РФ, 2013. - 67 с.

7. Бобылев Ю. Н. Налогообложение минерально-сырьевого сектора экономики / Ю. Н. Бобылев, М. Ю. Турунцева. - М. : Ин-т Гайдара, 2010. - 200 с.

8. Новак А. В. Зеленый свет - локомотиву экономики / А. В. Новак // Бурение и нефть. -2012 . - № 8. - С. 3-5.

\section{References}

1. Aganbegyan A. G. et al. Intensifikatsiya i effektivnost' sotsialisticheskogo proizvodstva [Intensification and efficiency of socialist production]. Moscow, Nauka Publ., 1988. 407 p.

2. Shmelev N. P. V poiskakh zdravogo smysla. Dvadtsat' let rossiiskikh ekonomicheskikh reform [In search for common sense. Twenty years of Rusian economic reforms]. Moscow, Ves' mir Publ., 2009. 514 p.

${ }^{5}$ Фонд развития промышленности РФ получил 20 млрд руб. URL: http://www.vestifinance.ru/ articles/51520.

\section{Baikal Research Journal}


3. Gaidar Ye. T. Gibel' imperii. Uroki dlya sovremennoi Rossii [Fall of the Empire. Lessons for Modern Russia]. 2nd ed. Moscow, ROSSPEN Publ., 2006. 448 p.

4. Gurvich E. T. Oil and gas rent in Russian economy. Voprosy ekonomiki $=$ Issues of Economy, 2010, no. 11, pp. 4-24. (In Russian).

5. Papchenkova M. Neftyaniki rasschityvayut dobit'sya snizheniya nalogovoi nagruzki izza padeniya tseny na neft' [Oil workers expect to obtain decrease of taxation burden due to downturn in oil prices]. Available at: http://www.vedomosti.ru/business/articles/2015/02/02/ novaya-cena-manevra. (In Russian).

6. Bobylev Yu. N. Mirovoi opyt nalogooblozheniya dobyvayushchei promyshlennosti [World experience of taxation in mining industry]. Moscow, Russian Presidential Academy of National Economy and Public Administration Publ., 2013. 67 p.

7. Bobylev Yu. N., Turuntseva M. Yu. Nalogooblozhenie mineral'no-syr'evogo sektora ekonomiki [Taxation of mineral and raw material sector of economy]. Moscow, Gaidar Institute Publ., 2010. 200 p.

8. Novak A. V. Green light to locomotive of economy. Burenie $i$ neft' = Drilling and Oil, 2012, no. 8, pp. 3-5. (In Russian).

\section{Информация об авторах}

Кородюк Игорь Степанович - доктор экономических наук, профессор, заведующий кафедрой экономики и управления бизнесом, Байкальский государственный университет, 664003, г. Иркутск, ул. Ленина, 11, e-mail: KorodukIS@bgu.ru.

Трофимов Сергей Евгеньевич - ассистент, кафедра экономики и управления бизнесом, Байкальский государственный университет, 664003, г. Иркутск, ул. Ленина, 11, e-mail: tennisist91@mail.ru.

\section{Authors}

Igor S. Korodyuk - Doctor habil. (Economics), Professor, Head of Chair of Economics and Business Management, Baikal State University, 11 Lenin St., 664003, Irkutsk, Russian Federation; e-mail: KorodukIS@bgu.ru.

Sergey E. Trofimov - Assistant Lecturer, Chair of Economics and Business Management, Baikal State University, 11 Lenin St., 664003, Irkutsk, Russian Federation; e-mail: tennisist91@mail.ru.

\section{Библиографическое описание статьи}

Кородюк И. С. Нефтегазовый комплекс России как объект государственного регулирования / И. С. Кородюк, С. Е. Трофимов // Baikal Research Journal. - 2017. - T. 8, № 2. - DOI: $10.17150 / 2411-6262.2017 .8(2) .18$.

\section{Reference to article}

Korodyuk I. S., Trofimov S. E. Russian oil and gas complex as an object of governmental regulation. Baikal Research Journal, 2017, vol. 8, no. 2. DOI: 10.17150/2411-6262.2017.8(2).18. (In Russian).

\section{Baikal Research Journal}

